\title{
OTOÑOS Y OTRAS LUCES: \\ LA LUZ DEL MUNDO COMO \\ PÉRDIDA Y EMERGENCIA
}

\author{
BÉNÉDicte Mathios
}

Université Blaise Pascal (Clermont-Ferrand)

El último libro publicado en vida por Ángel González se inserta en la continuidad de las temáticas claves de su obra, o sea tiempo, amor, historia, poesía. Su manera de apoderarse de ellas se sitúa ella también en la continuación de la obra, pero, al publicarse unos nueve años después de Deixis en fantasma (González, 1992), propone Otoños y otras luces (González, 2001) el balance global de una vida, de una situación sociopolítica, del mismo hecho de existir, de crear, lo que le da una dimensión meditativa a este libro. Este poemario revela cierta forma de perfección estructural, conviviendo con la habitual soltura y proximidad ${ }^{1}$ del lenguaje poético gonzaliano. Dicha estructura global, en cuatro partes, en vez de cerrarse sobre sí misma, se termina en una pregunta que recuerda la tonalidad del conjunto y lo abre a un cuestionamiento filosófico. Sin dejar de ser poesía, y a pesar de la tonalidad sombría que contiene, el libro es la expresión pulida de un deseo vital y mutual de existir circulando entre el yo y los otros, mujer amada, poetas amigos contemporáneos.

Desde el punto de vista temático, en la primera parte, titulada "Otoños», se declinan varias acepciones de la noción de otoño. En la cuarta y última parte viene a desarrollarse un tema complementario del otoño por lo visual que, como este, implica, o sea el tema de la «luz». La segunda parte, «La luz a ti debida», se dedica a una relación estrecha con la mujer amada que crea un modo específico de relacionarse con el mundo y por consiguiente con el 
lenguaje poético. La tercera parte es todo un homenaje dedicado a Claudio Rodríguez y a su voz poética: «la infinita materia de tu canto» (González, 2001: 57). El conjunto define, mediante la perspectiva del sujeto poético, un «estar vivo», en el que las sensaciones que permiten acceder al mismo mundo van perdiéndose a la vez que persisten: en esta tensión estriba la relación del poeta con las cosas y cada cual es susceptible de reconocerse en esta aprehensión del mundo, ya que la complejidad de la enunciación propuesta hace de esta poesía un objeto sensorial y reflexivo a la vez.

A partir de estas primeras aproximaciones, nos dedicaremos a estudiar más detalladamente los cuatro siguientes puntos: la enunciación y sus rasgos definitorios, las declinaciones del otoño y de la luz en la primera y en la cuarta parte y las varias significaciones que acarrean, así como las sensaciones de pérdida y supervivencia, el amor como relación con el mundo y acceso al lenguaje poético, el homenaje y su impacto en la voz poética.

\section{MODALIDADES DE ENUNCIACIÓN Y VOZ}

Llama la atención la variedad de los procedimientos enunciativos en este poemario. El «yo», contemplando lo circundante y meditando, a veces narrando, aparece en nueve poemas, más particularmente situados en la primera y en la última parte del poemario. La relación entre primera y segunda persona del singular concierne catorce poemas, entre los cuales siete son de índole amorosa, cinco dedicados al poeta amigo Claudio Rodríguez, uno evocando la llegada del día como «deslumbrante epifanía» (González, 2001: 73) del sueño y otro dirigiéndose a un «tú » que no es sino el propio corazón del sujeto poético (ibíd.: 77). El uso de la tercera persona del singular masculina o femenina remite a una posibilidad de narrar, de evocar, de reflexionar sobre la percepción y las relaciones del hombre con la realidad, en especial la realidad sensible. El «nosotros», por su parte, viene a abarcar el destino de la humanidad en seis poemas, los cuales a veces también son evocaciones o contemplaciones, y se sitúan exclusivamente en la primera y en la última parte; consideran el destino de la humanidad, mientras se miran el otoño y la luz. La multiplicidad de los puntos de vista induce en el lector la sensación de pasar de una a otra dimensión de lo vivido, lo cual es característico de la obra gonzaliana en general, que coloca al 
lector en el primer sitio de la percepción, como si de él se tratara, coexistiendo así individualidad y universalidad.

Otra característica esencial en este poemario, que viene a completar las distintas posturas de su locutor recordando cierta tradición retórica y poética, consiste en la presencia al final de cada poema de una frase sintética, fuerte, que viene a desempeñar el papel de la agudeza o del concepto que finalizan los poemas barrocos, en especial los sonetos. El propósito de estos poemas es, pues, ser intensos como lo fueron los poemas clásicos, con una estructura que se les parece aunque su forma sea «libre» con mayoría de heptasílabos y endecasílabos, versos que recuerdan la silva, pero con la soltura y la libertad acumuladas por la poesía hispánica a lo largo de la modernidad y de la postmodernidad que tiene totalmente asimiladas el poeta.

\section{OTOÑOS Y LUCES:}

\section{VARIACIONES Y SIIMBOLOS}

El tema del otoño corre a lo largo de la primera parte del poemario. El otoño, de estación, pasa a convertirse en una serie de motivos y de símbolos ${ }^{2}$, reuniéndose todos alrededor del tema de la pérdida, pero con unas extrañezas que caracterizan esta voz y la hacen escapar a lo trillado de una evocación del otoño en poesía, motivo romántico por excelencia. En el primer poema, «El otoño se acerca» (González, 2001: 11), el otoño se asimila a un animal o a un ser humano, connotados en el verbo «se acerca» y su complemento de modo "con muy poco ruido». En un estado de aparente inmovilidad, surge (véase la conjunción «pero» del verso 7) un doble fenómeno efimero: «silencio» y «luz»; de ahí la frase coloquial "ha pasado / un ángel», que rompe la tonalidad lírica, la cual retoma su hilo en el verso 10, encabalgado, oración relativa definiendo dicho «ángel» como fenómeno lingüístico, pues se señala cómo se «llamaba» y se enumeran los nombres posibles: «luz, o fuego, o vida» (v. 10). Luego la agudeza, con la implicación del pronombre colectivo «nosotros», viene a concluir abruptamente lo que fue una parábola, para que el lector saque sus conclusiones: «Y lo perdimos para siempre» (ibíd.). No se puede hablar de una poesía romántica que exprese explícitamente sentimientos de pérdida, tampoco es

2 Como lo sugiere Andrew P. Debicki en su artículo «Símbolo y experiencia en Otoños y otras luces» (2002). 
poesía descriptiva aunque sí es sinestésica ${ }^{3}$ y alegórica ${ }^{4}$, según implica la estética del autor; la evocación es extraña, situada en una duración y manifestando una ruptura, antes del balance final.Ya se expresa desde este primer poema la tonalidad del poemario.

En «Entonces» (González, 2001: 13-14), el poema siguiente, se considera el otoño como símbolo de un pasado - colectivodificil; en esta lógica, en los primeros tres versos, el otoño «es» la primavera. O sea que ya desde la primavera, los colores se hacen otoñales. Lo interesante es, en la parte "descriptiva» del segundo movimiento, la capacidad del tiempo inestable de ser agente de transformación de los colores del paisaje, hasta de transfigurarlos mediante la lluvia: «¿De cuándo ese carmín que fue violeta? / ¿De dónde / el oro que era ocre hace un instante?» La dimensión sonora viene a completar en los versos siguientes el conjunto, pero también a romper con estas transformaciones o a «subjetivizarlas», tanto más cuanto que son versos con asonancias en «i»/«o», que vienen a encontrarse al final del adjetivo "desvaído» calificando el verde, luego también en el adjetivo «inquieto», que personifica el cielo, y aliteraciones en «l», «m», «s»y «r» características del verso 12: «Los silbos amarillos de los mirlos». La «confusión» que se le asocia al nosotros anuncia la caída final, que se coloca en la última estrofa, mezclando sensaciones fisicas, sentimientos («temor y nostalgia»), con una tercera estación, el «invierno»:

evocamos entonces

la verdad fría y desnuda de un invierno no sé si ya pasado o por venir.

Pero en este caso, lo simbólico de la expresión puede llevarnos a pensar, allende las percepciones del tiempo, en inviernos que simbolizan el franquismo ${ }^{5}$, dado que la problemática social que caracteriza la obra gonzaliana de los años 60, aunque parezca ausente del poemario, surge de vez en cuando, evocando el pasado dolorido y el presente inquietante, como por ejemplo en «Aquel tiempo»

3 El sonido se junta con lo visual: «apagadas cigarras, unos grillos apenas» (González, 2001: 11).

4 Con esta personificación: «un verano obstinado en perpetuarse» (González, 2001: 11).

5 Léase, en Sin esperanza, con convencimiento (1961), libro que ofrece una visión totalmente desilusionada, el poema titulado «El invierno» (González, 1994: 88), que contiene varios símbolos, y también, esparcido en la última estrofa, el título del poemario, emblemático de una poesía marcada por la guerra civil y el franquismo. 
(González, 2001: 65). En el caso de nuestro poema, el último verso, «no sé si ya pasado o por venir», tanto podría insertarse en una conversación banal sobre el tiempo que hace como en una reflexión llena de inquietud acerca del porvenir ${ }^{6}$ político, mediante la dilogía característica del manejo de los dobles sentidos en poesía y en esta en particular ${ }^{7}$. Esta dimensión social y política ocupa por completo un poema en el que ya desapareció el motivo del otoño, aunque se sitúa en la misma sección inicial del poemario: se trata de «Estampa de invierno" (ibíd.: 21), en el que, a las claras, se superponen recuerdos individuales y colectivos, mediante la metáfora del frío y de una ventana desquiciada que vienen a simbolizar la memoria dolorosa del sujeto. Lo colectivo surge en el segundo movimiento del poema, fantasmal, basado en el frío inicial, que provoca recuerdos visuales y sonoros, después de un primer movimiento con cruce de términos que evocan un frío presente, un sufrimiento físico y la agresión de los recuerdos:

No es de ahora, este frío.

Viene desde muy lejos:

de otras calles vacías y lluviosas, de remotas estancias en penumbra

pobladas solo por suspiros, de sótanos sombríos

en cuyos muros reverbera el miedo.

Pero el otoño viene a encarnarse en otros símbolos y sentidos, otra vez vinculados, como en los poemas anteriormente comentados, con la noción de pérdida. Se convierte por ejemplo en el espacio del amor perdido (tópico pero renovado aquí), en el poema muy depurado «Casi invierno» (González, 2001: 15), con elementos precisos, espaciales, definiendo la pena amorosa, en una estética que recuerda la endecha (heptasílabos dominantes en siete de los diez versos que contiene), la estética machadiana y también hernandiana por lo depurado y denso de la desesperación que se expresa. La narración breve de los dos primeros versos, el amplio movimiento siguiente, averbal, el dialogismo, con pregunta y respuesta, que clausura el poema con letra de canción popular ${ }^{8}$,

6 Siendo el porvenir otro tema clave de la obra, por ejemplo en el poema «Porvenir» (González, 1994: 89).

7 Véase García Martín, 1997: 80-95.

8 O sea, «De los álamos vengo, madre» (siglo XVI). Su uso recuerda a Blas de Otero, pues la cita él también en un poema de En castellano, que comenta Carlos Bousoño (1985: 556). 
vienen a caracterizar ampliamente la voz poemática, como impregnada por su "otoño", que es espacio natural pero también poemático, el de la pérdida de la persona amada. Otro poema perteneciente a la segunda parte, «La luz a ti debida», basado en la temática amorosa, podría entroncarse con este: se titula "Canción de amiga» (ibíd.: 39). Es un poema cuyo título y temática recuerdan las antiguas «cantigas de amor»; el frío que, de una vez, lo ha invadido todo ${ }^{9}$, viene a integrarse en el sujeto y a encarnar su pena amorosa basada en la pérdida de la amada, marcada por la casi reiteración del alejandrino inicial al final del poema: «Nadie recuerda un invierno tan frío como este», que se convierte en «No recuerdo un invierno tan frío como este». Con el cambio de sujeto gramatical, se pasa de una frase deliberadamente trivial y cotidiana a la situación única del sujeto.

Un poema breve, formado por tres estrofas polimétricas de cuatro versos, cuya situación espacial y temporal sustituye el tema otoñal (final de una estación) por el del crepúsculo (final de un día), es «Este cielo» (González, 2001:19). En este poema se asimilan otoño, crepúsculo, final de la música, siendo el tema principal el de la permanencia anterior a la pérdida definitiva de la luz y del sonido conjuntamente, deseo de permanencia que viene a manifestarse aquí mediante adverbios tales como «aún», «todavía», adjetivos tales como «remansada» y el sustantivo "moratoria», cuya dimensión jurídica infunde humor a pesar de la tonalidad global melancólica. Se notan evocaciones suaves y sinestésicas preciosas en las dos primeras estrofas, cuyo ritmo, basado en versos métricos sueltos (algunos de los cuales se encabalgan), viene a insertarse con facilidad en el oído del lector:

\author{
El brillo del crepúsculo, \\ llamarada del día \\ que proclama que el día ha terminado \\ cuando aún es de día. \\ El acorde final que, \\ resonante, \\ dice el fin de la música \\ mientras la música se oye todavía.
}

9 Nótese la epífora «de hielo», que completa los tres versos descriptivos, paisajísti$\cos$, de la segunda estrofa. 
La tercera y última estrofa, por su parte, revela la percepción fisica que tiene el sujeto de esta luz y la traspone a la temática del tiempo que huye, pero paradójicamente en un presente «estabilizado", antes de desaparecer el acceso a la luz y al mundo. Este desaparecer concierne justamente el poemario en cuanto a temáticas (otoños, luces) tanto como a significados y formas:

Este cielo de otoño, su imagen remansada en mis pupilas, piadosa moratoria que la tarde concede a la débil penumbra que aún me habita.

Este tema volverá a aparecer en la última parte del poemario, más específicamente en el poema titulado «Un largo adiós» (González, 2001: 69), que alegoriza, ritma y sonoriza el paso de día a noche (o sea de luz a sombra) que coexiste con la problemática del paso del tiempo; la alegoría personifica los elementos, entre ellos el día, el sol. Este último «tira del día» (v. 4) como si de un niño se tratara: la visión es lúdica. La intervención de la naturaleza a lo largo de los versos 6 a 14, basada mayoritariamente en encabalgamientos, permite al locutor plural «nosotros» verse iluminado todavía, mientras el sentido se construye en movimientos contrarios: «tirar de» vs. «retener», manifestado este último por verbos que, concretos como lo son «enredar» $\mathrm{y}$ «sostener en vilo», remiten respectivamente al canto de los pájaros y a la brisa, a elementos pues intangibles pero perceptibles. Los dos últimos versos, endecasilábicos, subrayan un proceso alquímico que se hace poético por la presencia de verbos que implican, en la inmovilidad del día, una transformación interna, la de la índole de la luz; es así como, trabajando con tres sinéresis que «anudan» vocales entre sí, y sonidos vocálicos como «e», «a», «O», el poeta transforma «oro» en «plata»y día en... día con la permanencia paradójica de su luz al salir la luna. Este poema participa, gracias a esta metamorfosis que parece salida de un cuento maravilloso ${ }^{10}$, de la toma de consciencia del paso del tiempo, percibido con los sentidos del oído y de la vista, según una perspectiva sinestésica a la que recurrió frecuentemente el poeta a lo largo de su obra.

Dos poemas con interrogaciones fuertes, que le aportan al poemario una dimensión filosófica, vienen a «reflexionar sobre» más

10 Recordemos el papel desempeñado por «el objeto mágico» en la tipología de los personajes de los cuentos explicada en el tercer capítulo de Morphologie du conte, de Vladimir Propp ([1928] 1970: 55). 
que a evocar el otoño y la pérdida de los sentidos que viene a simbolizar el paso de una estación a otra: son «Ciego» (González, 2001: 17) y "Aquí o allí» (ibíd.: 23). El primer poema consta de cuatro estrofas muy breves: las dos primeras interrogan la fuente de la ceguera y de la sordera de un personaje masculino de la tercera persona, cuestionando su estado la voz impersonal y dialogística con oraciones nominales que inician las dos primeras estrofas: «¿Ciego a qué?», "¿Sordo a qué?». Se ahonda en el tema, que no se queda en el nivel de los sentidos fisicos sino que apunta a otro significado: ser ciego "no a la luz», sino «a la vida». En efecto, marca tanto una percepción que se pierde como una actitud moral que connota esta pérdida. La tercera estrofa, polimétrica, brevísima también (bisílabo, tetrasílabos y un pentasílabo), sintetiza esta pérdida del contacto con el mundo. La última estrofa, una cuarteta heptasilábica asonantada, propone una explicación que implica el final del otoño (o sea de la luz y de la vida, en la lógica del poemario): la totalidad del mundo desaparece detrás de la nieve caída repentinamente:

\author{
Como si al mundo entero \\ una nevada súbita \\ lo hubiese recubierto \\ de silencio y blancura.
}

Bien se ve que en los sentidos y en la percepción reside la capacidad de que exista el mundo según el poeta, recordando así interrogaciones científicas ${ }^{11}$. De ahí otro poema, desconectado del tema de las estaciones pero próximo a las temáticas del último poema citado: "Aquí o allí (González, 2001: 23). Interroga sobre los sentidos y la situación del sujeto en el mundo, que queda sin saber si su aprehensión del mundo depende de él, o si existe fuera del yo «el secreto corazón del mundo» (v. 5) para darle su sentido a la existencia del yo; y concluye con un nuevo sentimiento de "pérdida» fundamental, expresada espacialmente por los dos adverbios que configuran el título, reflejando la proximidad y el alejamiento implicados por las interrogaciones que dimanan del poema.

En lo concerniente al título de la sección final, «Otras luces», se aprecia que el adjetivo "otras» implica una asimilación entre otoño y luz, como si los otoños ya evocados, a los que se añaden las temáticas respectivamente elegíacas y amorosas de las dos partes

11 «Si nos perceptions visuelles dépendent de notre cerveau, est-ce bien la réalité que nous percevons? Ou bien l'image projetée de notre organisation cérébrale?» (Philippe Meyer, 1997). 
centrales, constituyeran otras tantas luces, otras tantas maneras de conocer o desconocer el mundo y de reflexionar sobre las razones de su existencia. Lógicamente colocado al principio de la sección, el poema titulado «Alba en Cazorla» (González, 2001:61-62) viene a ilustrar con un ejemplo concreto las preguntas planteadas en el último poema de la primera sección, "Aquí o alli»", que acabamos de mencionar. Se esparcen los dieciséis primeros versos (entre seis y trece sílabas métricas) en cuatro estrofas de cinco, cuatro, dos y cinco versos, para describir varios aspectos del alba, situada en un espacio reconocible, toponímico, citado en el título. El poeta empieza por los sonidos que van vinculados con este momento, en especial el canto del gallo, tópico evocado con humor en la primera estrofa, con el término "cacareada», y la interrogación irónica sobre el significado de estos "clarines», metáfora in absentia con connotación musical ${ }^{12}$ que propone el poeta para designar este canto. Pero el poeta se va a dedicar luego a la dimensión visual de la llegada de la luz, no sin aludir, en modo sinestésico, a unos sonidos como los balidos que ocupan el espacio en hueco de un valle en el paréntesis que se extiende a lo largo de los versos 12 a 16 . Son signos apenas del alumbramiento futuro que describe el poeta, evocando «atisbos de luz» surgidos de un abismo, un «rubor azul» asimilado a un «renacer» del cielo ${ }^{13}$. Los últimos cinco endecasílabos se reúnen en una reflexión a partir del paisaje matinal sobre el origen de la luz, o sea de las cosas:

\section{Enigmática luz, tan clara y pura que tan solo se ve en lo que desvela. ¿De dónde viene este esplendor creciente? No es aún la luz la que ilumina al mundo; el mundo iluminado es quien la enciende.}

La interrogación atañe la percepción, pero también abarca un cuestionamiento más amplio sobre la capacidad por parte del mundo de iluminar o de ser iluminado. Se va acercando esta pregunta nacida de una contemplación a la expresión de una reflexión metafísica acerca del porqué y del cómo de la existencia del mundo, interrogación que volverá a surgir en el último poema, «Aquella luz» (González, 2001: 79-80). Los poemas siguientes desarrollarán

12 Dimensión de la que no está desprovista la obra gonzaliana, como se sabe.Véase por ejemplo el poema de Grado elemental (1962) titulado "Penúltima nostalgia» (González, 1994: 135-139), que basa la evocación del siglo XX en sensaciones musicales, entre otras.

13 ¿Referencia al Jorge Guillén de Cántico? 
otros cuestionamientos acerca de la luz y de sus símbolos, pero el poema inicial no deja de influir en aquellos por plantear preguntas esenciales, lo que parece ser una de las características de este poemario que casi concluye una obra.

Lo que llama la atención es que todas estas luces o bien no se consiguen, o bien se pierden, o bien pertenecen al pasado — pasado que, a su vez, cuestiona el poeta-, o bien se contemplan, pero desde su pérdida; de ahí la coherencia del poemario, que también aborda temáticas de un recorrido vital individual insertado en un contexto histórico contemporáneo cuyas huellas persisten, tal como ocurre en dos poemas, el uno con perspectiva más bien individual, el otro más bien colectivo: respectivamente, «Viejo tapiz» (González, 2001: 63-64) y "Aquel tiempo» (ibíd.: 65). El primero representa al locutor niño, cuyo destino se reconoce en clave simbólica, hasta mítica, con la metáfora continuada de un tapiz «que urdían incansables / las obstinadas manos amorosas», sinécdoque que viene a entroncarse con la figura de las Parcas simbolizando tradicionalmente el destino humano. El contexto en el que el poeta inserta esta escena en pretérito imperfecto remite a la Historia, presente a lo largo de la obra, al episodio de la guerra civil, y más precisamente a las huellas, concretas y morales, que dejó el conflicto a lo largo de una dictadura que conoció el poeta hasta los años 70, lo que demuestra el primer verso y su continuación en encabalgamientos en los siete versos siguientes:

Todo el mundo era pobre en aquel tiempo,
todos entretejían
sin saberlo
—a veces sonreían-
los hilos de tristeza
que formaban la trama de la vida
(inconsistente tela, pero
qué estambre terco, la esperanza).

El léxico del tejer, mediante la palabra polisémica «trama», está omnipresente en este autorretrato de la España de la guerra y de la posguerra. La luz, que se sitúa en «un extremo de aquel tapiz sombrío» metafórico, participa en la visión del niño corriendo «hacia el espacio luminoso", al que no accede, como se nota en la última estrofa, muy clara y tajante, según la estética del poemario. La luz en este caso es la de un ideal individual (en el que pueden reconocerse los lectores), fracasado frente al contexto histórico. La veta moral que bien se conoce en la obra de Ángel González completa pues esta representación anclada 
en lo simbólico en el siguiente poema, "Aquel tiempo» (González, 2001: 65), en el que se nota una ausencia completa de luz, al definirse un «tiempo sombrío», caracterizado por su inmoralidad hasta el tiempo presente, donde las palabras finales («traición», «olvido»), duras ellas también, remiten a acontecimientos trágicos no totalmente arreglados a raíz del final del franquismo.

Unas vivencias más personales también van entroncadas con el motivo de la luz, su pérdida, su ambivalencia, y la capacidad del sujeto para retener el pasado. El poema en dos partes titulado «Versos amebeos» (González, 2001: 71-73), en referencia a formas de la Edad Media, le atribuye a la luz un papel destructor, que lleva a la desdicha y al despertar del sufrimiento, o bien constituye una «epifanía» (o "aparición») de lo luminoso como manifestación de la dicha, aunque situada toda en el pasado. Pasado que viene a ser el tema principal de otros dos poemas: «Tan lejos» (ibíd.: 75), interrogación sobre el pasado como sueño o realidad, y «Dos veces la misma melodía» (ibíd.: 77), en el que el pasado, «ayer ya muerto", se hace reiterado canto, y donde el campo semántico dominante es el del contrapunto musical conjuntamente con el del río, motivo que a las claras recuerda el del río simbólico de Heráclito $^{14}$. El poema final, por su parte, «Aquella luz» (ibíd.: 79-80), sintetiza a la vez que abre una interrogación sobre una aludida «luz» en la que cualquier lector puede ver lo que quiere ${ }^{15}$ : «Aquella luz que iluminaba todo / lo que en nuestro deseo se encendía, / ¿no volverá a brillar?». En «Aquella luz» están resumidas las principales temáticas del libro: la luz y el otoño actúan conjuntamente para iluminar el mundo, les sucede el invierno, con imagen recta de «ordenación» de «la vida de los hombres» (v. 15), y termina el poema en una interrogación colectiva, basada en el pronombre «nosotros», acerca de la pérdida de esta luz, la cual se asimila a la energía vital del deseo, vinculándose así el amor con la dimensión metafisica que trasciende el balance de una vida y de una obra nutridas de historia:

Aquella luz que iluminaba todo lo que en nuestro deseo se encendía ¿no volverá a brillar?

14 Léanse otros poemas gonzalianos, como, por ejemplo, «Glosas a Heráclito» (González, 1994: 302).

15 Esta interrogación final no deja de recordar la introducción a Poemas (González, 2003: 26), en la que evoca el poeta la libertad interpretativa dejada al lector, sabiendo el autor «las circunstancias» del poema y las intenciones, que sin embargo resultan insuficientes para entender el poema. 
La metapoesía, de la que no carece la obra gonzaliana, se expresa por su parte tanto en la evocación de la situación del sujeto que definen los poemas hasta ahora evocados, o sea la mayoría de los textos constituyentes de la primera y última partes del libro, como en una segunda parte enteramente dedicada a la veta amorosa, y también en la tercera, homenaje en cinco poemas a Claudio Rodríguez.

Amor, mundo y lenguaje poético van estrechamente ligados unos a otros en los poemas de la segunda parte, «La luz a ti debida». Se puede considerar el primer poema, «Estos poemas» (González, 2001: 27), evocador de un título de Blas de Otero en el poemario Ancia $(1958)^{16}$, como un arte poética, una suerte de anti-descripción del proceso creador que recuerda poemas anteriores referidos a la vez a la dificultad de fiarse del lenguaje, a la dificultad de que el lenguaje actúe sobre la realidad (por ejemplo, «Preámbulo a un silencio", de Tratado de urbanismo [1967]), de que el lenguaje original, nacido de una necesidad por así decirlo «fisica» de expresión, se vuelva a encontrar (véase el poemario Palabra sobre palabra [1965]), y por fin a la definición del poema como un "grupo de palabras» frágil a la hora de restituir la experiencia frente al efecto destructor del tiempo (así, los «Poemas elegíacos» de Muestra, corregida y aumentada, de algunos procedimientos narrativos y de las actitudes sentimentales que habitualmente comportan [1977]). La composición «Estos poemas», que por su uso del plural funciona como denominador común respecto del conjunto de poemas siguientes, al definir el proceso creador, también recuerda el becqueriano "poesía eres tú» ya desde el primer verso: «Estos poemas los desencadenaste tú». O sea que participa la alteridad amorosa en la creación poética, algo que va a demostrar la mayor parte de los siguientes poemas. Otro elemento de definición es lo aleatorio del poema, e indirectamente, su libertad de expresión, ligada al hecho de que la experiencia vital es múltiple, de variada índole, como lo muestran los dos últimos endecasílabos y como lo demostraron poemas de distintas épocas en esta obra, incluso los más deliberadamente sociales ${ }^{17}$ : "y hacen un ruido melodioso o triste, / lo mismo que dos cuerpos que se aman». En el presente ejemplo, los poemas se parecen a

16 Véase el soneto titulado «Estos sonetos» (Otero, 1958: 33).

17 Por ejemplo, las dos perspectivas propuestas para cada temática abordada en la primera parte de Tratado de urbanismo. 
un acto amoroso, de ahí que en la mayor parte de esta sección la enunciación se haya construido alrededor de la relación entre el «tú» que representa a la mujer amada y el «yo» sujeto, en situación de mutua contemplación y también de mirada a la realidad circundante. Es así como el poema titulado «Fiel» (ibíd.: 31) propone una contemplación del «tú " por el «yo» en la luz del paisaje que desaparece, él mismo contemplado por el «tú», de ahí una cadena de miradas entre «yo», «túı, "paisaje», que se desprende de los cuatro primeros versos:

\section{Cuántas veces te has vuelto, en heliotropo convertida, a mirar lo que amabas, deslumbrada.}

Así te he visto yo desde la sombra.

De hecho, el papel otorgado a la mirada a la mujer amada, admirada o activa en el intercambio de miradas entre "yo» y «tú", así como el poder «transformador» de las palabras al evocar, en especial, a la mujer amada, constituyen los dos ejes principales de las relaciones entre lo amoroso y la escritura poética. Es así como, en los poemas titulados «Quise» (González, 2001: 33) y «La luz a ti debida» (ibíd.: 45), se sustituye la mirada del yo por la del tú, la cual también recibe la influencia de la mirada del yo en una representación desengañada, en especial en el primer poema citado, iniciándose así: "Quise mirar el mundo con tus ojos», y concluyendo así»: «Y fuiste tú la que acabaste viendo / el fracaso del mundo con las mías», aludiendo este último pronombre a la palabra "pupilas», citada justo antes. Es toda una tonalidad del desencanto, presente ya desde «Para que yo me llame Ángel González» (González, 1956: 13), que vuelve a expresarse aquí, en la interacción de las miradas, imagen que hunde sus raíces en lejanas influencias petrarquistas integradas en toda la poesía europea.

En el segundo poema citado, «La luz a ti debida» (González, 2001: 45), el poeta, intentando escapar al paso del tiempo, se agarra al presente, consciente de la destrucción próxima. En el primer movimiento, escrito todo en tiempo futuro, el poeta crea su propio sistema enunciativo, en el que el «yo» mira al «tú», en cuyos ojos («tus pupilas», v. 4) se refleja el conjunto del mundo al que se le asocia la noción de belleza, y, en el centro de este centro, está el «tú» como fuente de luz. El segundo movimiento se basa en el enlace del «yo» y del «tú», que, como origen de la representación poética, 
define un punto central basado en la alteridad: así lo manifiesta la sintaxis del verso 12 , «mírame mirarte».

En cuanto al papel «transformador» de las palabras, el poeta se fia de él en tres poemas (incluso en otros dos más, cuya tonalidad es humorística [González, 2001:29, 41-42]), pero siempre a partir del referente constituido por la figura femenina, que «activa» las palabras $^{18}$. De ahí títulos programáticos tales como «A veces, un cuerpo puede modificar un nombre» (González, 2001: 35), «También un nombre puede modificar un cuerpo» (ibíd.: 37-38), "Nada más bello» (ibíd.: 43). El primero induce la creencia en el poder de las palabras para metamorfosear la realidad (a diferencia de la desilusión característica de Tratado de urbanismo), con la condición de que la parte carnal, sensorial, quede bajo la responsabilidad del tú. El segundo poema interroga el papel evocador de los nombres de mujer, dándoles a las palabras la capacidad de «iluminar» el tú, el cual existe de por sí, y cuya presencia está "completada», «mejorada» por las palabras, aunque no pueden sustituirle. En «Nada más bello», el tú viene, por su parte, a sobrepasar la belleza de lo inanimado, comparando el poema con un rayo de sol sobre la nieve y una sonrisa surgida en un rostro en lágrimas. Todo un hipotexto barroco se adivina bajo este símil, que le da otra vez a la figura femenina un poder embellecedor e iluminador, y por consiguiente poético.

\section{HOMENAJE Y VOZ POÉTICA}

La relación del sujeto con poetas contemporáneos resulta importante a lo largo de toda la obra gonzaliana ${ }^{19}$, mediante citas y alusiones. Cinco poemas, reunidos bajo el título «Glosas en homenaje a C. R.», y formando una sección entera de Otoños y otras luces, constituyen un homenaje tributado a Claudio Rodríguez e indirectamente expresan una estética propia de Ángel González, a través de la relación del sujeto con el mundo, no solo mediante los códigos ofrecidos por el lenguaje. Ángel González recurre a varios

18 Véase toda la reflexión sobre la capacidad expresiva de las palabras desarrollada en el poemario de 1965 titulado Palabra sobre palabra, que consta de cinco poemas.

19 En Sin esperanza, con convencimiento (1961), Muestra, corregida y aumentada, de algunos procedimientos narrativos $y$ de las actitudes sentimentales que habitualmente comportan (1977), Prosemas o menos (1985), Deixis en fantasma (1992) y Otoños y otras luces (2001) encontramos referencias directas o implícitas a Vicente Aleixandre, Blas de Otero, Jorge Guillén, Antonio Machado y Claudio Rodríguez. 
procedimientos; es así como, por ejemplo, cita en el primer poema un extracto del poema "Canto del despertar», que forma parte del poemario Don de la ebriedad (1953) de Claudio Rodríguez: «Aquí sí es peligroso» (Rodríguez, 1992: 45). En las dos últimas estrofas, el oxímoron final "peligro hermoso» remite a esta cita. En el tercer poema reconocemos la famosa frase «no poseemos, / vemos», tomada del poemario Alianza y condena $(1965)^{20}$. En el cuarto poema (González, 2001: 55), la palabra «vuelo» alude al poemario El vuelo de la celebración (1976), así como a una red de significados que la vinculan con la poesía mística española.

Al valerse de los tiempos del pasado el autor subraya el carácter elegíaco de los poemas dedicados a Claudio Rodríguez, muerto en 1999. En el primer movimiento del primer poema están evocados espacios y sensaciones: así, por ejemplo, «la luz de las llanuras altas», «[el] rumor del río Duero». En un segundo tiempo esta percepción inicial simboliza la búsqueda de la verdad (González, 2001: 49):

en el fondo, te estabas refiriendo a la pureza, a la honda verdad que se desprende de lo que vive en plenitud y es libre.

El oxímoron final «peligro hermoso» remite a una forma de fascinación a la par que a una inquietud frente a dicha percepción. Un temor que se concreta mediante la imagen de un cuerpo ciego, metáfora del destino del poeta y de los seres humanos en general: «Para quien anda a tientas, / y no sabe, / la noche abierta es un peligro hermoso».

El segundo poema expresa un deseo de interpenetración entre el «tú» y la naturaleza, describiéndose así la poética de Claudio Rodríguez, en especial el lugar de su sujeto en la realidad mediante una serie de verbos que connotan la voluntad de participación del sujeto en dicha realidad: "ser en lo que te asombraba», "estar en ello», «participar en», «compartir», «alentar en», «orear», «diluirte en». Se trata de asimilarse a las cosas que, como el paisaje, son personificadas: "para que la llanura te respire».

A pesar de ello, la cita extraída de la obra de Claudio Rodríguez, «no poseemos, / vemos», mantiene al sujeto «fuera» del mundo; se hace "espía, delator del mundo», o sea una mirada exterior, a

20 Palabras situadas al principio del poema «Porque no poseemos» (Rodríguez, 1993: 121). 
pesar de lo que se quisiera, esto es, imprimir la realidad con huellas de una presencia, como se nota en esta cita de un poema de Claudio Rodríguez:

[...] Pero miro,

cojo fervor, y la mirada se hace

beso, ya no sé si de amor o traicionero.

Quiere acuñar las cosas,

detener su hosca prisa

de adiós, vestir, cubrir

su feroz desnudez de despedida

con lo que sea: con esa membrana

delicada del aire,

aunque fuera tan solo

con la sutil ternura

del velo que separa las celdillas

de la granada (Rodríguez, 1992: 133).

En su poema, Ángel González se refiere implícitamente a su propia obra, estando su locutor siempre en el corazón de las cosas, presencia que garantiza la percepción de cosas que no se pueden evocar ni transformar ${ }^{21}$, aunque, como lo escribe el hablante de Claudio Rodríguez, quiera «acuñar las cosas, / detener su hosca prisa / de adiós $[\ldots]$ ".

En el cuarto poema (González, 2001: 55), el locutor insiste en las cualidades del tú, según la tradición del panegírico en la elegía ${ }^{22}$, en especial el haber dominado el miedo, asociado por Claudio Rodríguez a un «amigo» tan temible como el tiempo ${ }^{23}$ : "Para vencer al miedo / te aliaste con el miedo», en un espacio propio, «el espacio prodigioso / donde pueden pisarse las estrellas». Al emplear la palabra «vuelo», el poeta se refiere al poemario de Claudio Rodríguez El vuelo de la celebración (1976), cuando leemos, en el poema «Hacia la luz»: «y para ver hay que elevar el cuerpo» (Rodríguez, 1993: 211); dicha imagen recuerda a su vez la poesía

21 En «Las palabras inútiles» (González, 1994: 178-179), el locutor se considera «espía de palabras» (v. 2), por culpa de su incapacidad para decir «lo que eres» (v. 6).

22 Las principales «fases» de la elegía tradicional son la presentación y el anuncio de la muerte, la lamentación y el llanto, el panegírico y la consolatio (Una referencia entre otras: Eduardo Camacho Guizado, La elegía funeral en la poesía española [1969]).

23 «Es el tiempo, es el miedo / los que más enseñan / nuestra miseria y nuestra riqueza» (Rodríguez, 1993: 199). 
mística, por ejemplo las Canciones del alma y el esposo de San Juan de la $\mathrm{Cruz}^{24}$.

Es así como estos cinco poemas constituyen homenajes a una obra en la que el cuerpo y sus percepciones participan de la búsqueda de un vínculo indisoluble entre el poeta y las $\operatorname{cosas}^{25}$. Claudio Rodríguez reivindica este vínculo en la introducción a Desde mis poemas, cuando describe su proyecto en El vuelo de la celebración (1976):

Celebrar lo que se abre y lo que se cierra desde todas las posibilidades vitales: la figura de las cosas, el poderío de las sensaciones que pueden desembocar en feracidad y en sequía. Es como una «animación», que recrea, fugitivamente, lo que nos sobrecoge y nos camina, y nos pule, y nos mejora. [...] El destino humano, con todos sus adjetivos.

Se nos ofrece aquí una idea amplia de la poesía de la experiencia, vivida tanto por el poeta como por su poesía.

\section{CONCLUSIÓN: SENSACIONES, ENTRE PÉRDIDA Y SUPERVIVENCIA}

Todo el poemario se basa en una tensión fuerte, un equilibrio precario entre la realidad, concebida según se puede percibir, y la pérdida progresiva de la eficacia de los sentidos. Esta noción entronca perfectamente con la de "otoño", estación que evoluciona desde la madurez estival hasta lo extremado del frío invernal, cuya simbología es importante para señalar el envejecimiento desde el que se expresa el sujeto poético (tema-clave en la obra gonzaliana ya desde Áspero mundo, de $1956^{26}$, y que no tiene que ver, finalmente, con la edad del autor, más bien se trata de una elección específica). El sentir de la realidad y su alejamiento progresivo también se unen al tema de la luz, como paso de una hora a otra, de un momento del día a otro, o sea del amanecer al día, o del día a la noche. La estrecha relación de esta poesía con el amor está directamente ligada con

24 Cuando por ejemplo dice la esposa: «voy de vuelo», y se transforma entonces en el discurso del esposo en paloma (De la Croix, 1997: 60).

25 «Gran parte de la poesía contemporánea — y no tan solo española— queda coja, inválida, y no únicamente por la absurda denominación de "verso libre", sino por la distancia esencial del lenguaje ante las cosas» (Rodríguez, 1992: 16).

26 Pensemos en «Para que yo me llame Ángel González» (González, 1994: 13). 
la aprehensión de la realidad, pero también con su representación artística, ya que se reúnen, en un sentido u otro, los sentidos de los amantes hacia el poema, en especial el de la vista. La complejidad reside en que dichos elementos, que intentamos aclarar desde el entramado de una voz en apariencia sencilla, se construyen con dosis diferentes según los poemas.

El poemario póstumo Nada grave, publicado en 2008, no será sino continuación, hasta respuesta y contrapunto, a Otoños y otras luces. La dilogía que preside el título general resume por sí sola la casi totalidad de la obra. «No hay nada grave», parece que nos diga el poeta, con toda la sabiduría de su edad y su estoicismo barroco; por otro lado, claro, nos habla de una nada grave que pesa sobre el ser humano, nada resultante del tiempo destructor cuya presencia corre a lo largo de toda la obra gonzaliana, ya desde Aspero mundo. Así es como la pregunta que concluye Otoños y otras luces ${ }^{27}$ viene contestada por este poemario pesimista pero amante todavía de las palabras y de los juegos infinitos que proponen, aunque sea para constatar el sin número de limitaciones que configuran la existencia del ser humano. Le contesta, de hecho, el conjunto del poemario póstumo, que, excepto raras excepciones, está escrito bajo el signo de la oscuridad, de lo sombrío, del «pedazo de sombra» con el que se autodefine el sujeto poético (González,2008:33),mientras que en Otoños y otras luces permanece vigente la percepción del mundo, él mismo hecho luz aunque esté oscureciéndose y se haga progresivamente inasequible.

27 «Aquella luz que iluminaba todo / lo que en nuestro deseo se encendía, / ¿no volverá a brillar?» (González, 2001: 80). 


\section{BIBLIOGRAFÍA}

Bousoño, Carlos (1985). Teoría de la expresión poética I, Madrid, Gredos.

Camacho Guizado, Eduardo (1969). La elegía funeral en la poesía española, Madrid, Gredos.

Debicki, Andrew P. (2002). «Símbolo y experiencia en Otoños y otras luces», Litoral [«Ángel González. Tiempo inseguro»], 233, pp. 202-205.

De la Croix, Jean (1997). Nuit obscure. Cantique spirituel (Édition bilingue), préf. José Ángel Valente, trad. Jacques Ancet, Paris, Éditions Gallimard.

García Martín, José Luis (1997). «Cuestión de procedimiento. La poesía última de Ángel González», en Guía para un encuentro con Ángel González, Langreo, Luna de Abajo, pp. 80-95.

GonzÁlez, Ángel (1994). Palabra sobre palabra, Barcelona, Seix Barral.

- (2001). Otoños y otras luces, Barcelona, Tusquets.

- (2003). Poemas, Madrid, Cátedra.

Meyer, Philippe (1997). L'cil et le cerveau, biophilosophie de la perception visuelle, Paris, Odile Jacob.

Otero, Blas de (1958). Ancia, Madrid,Visor.

Propp,Vladimir ([1928]1970). Morphologie du conte, Paris, Seuil.

Rodríguez, Claudio (1992). Desde mis poemas, Madrid, Cátedra.

- (1993). Hacia el canto, Universidad de Salamanca, Patrimonio Nacional.

VillenA, Luis Antonio de (2002). «Ángel González, recuerdos y celebraciones», Litoral [«Ángel González.Tiempo inseguro»], 233, pp. 189-192. 